\title{
Coloured filters may reduce symptoms of dyslexia in those with visual stress
}

\author{
Bruce J W Evans director of research ${ }^{1}$, Peter M Allen professor of optometry and visual science ${ }^{2}$ \\ ${ }^{1}$ Institute of Optometry, London SE1 6DS, UK; ${ }^{2}$ Department of Vision and Hearing Sciences and Vision and Eye Research Unit, Anglia Ruskin \\ University, Cambridge CB1 1PT, UK
}

Henderson and colleagues did not consider one obvious explanation for the endorsement of coloured filters by dyslexia charities: these charities are in close contact with their members, some of whom provide feedback on benefits from coloured filters. ${ }^{1}$ Coloured filters are not a treatment for dyslexia but reduce symptoms in individuals with visual stress, ${ }^{2}$ which affects only about one third of people with dyslexia. ${ }^{34}$ Consequently, studies that ask whether coloured filters treat reading difficulties will probably find that they do not. Reviews that ask the same question, such as those cited by Henderson and colleagues, will also be likely to produce a negative finding. We know of more than 20 studies of the effects of overlays on reading rate, and few of them were included in these reviews. These studies, published in peer reviewed journals, include various controls for placebo effects, none of which provides for an improvement in reading rate as great as that observed with an overlay. Uccula et al provide a balanced review. ${ }^{5}$

We accept that the diagnosis of visual stress is challenging and more research is needed. ${ }^{2}$ In the meantime, it would seem a sensible precaution for children with reading difficulties to be asked if words appear to blur or move, and if reading causes a headache. For such cases, the College of Optometrists' guidelines advocate ruling out conventional visual factors and screening with coloured overlays. If a child finds an overlay helpful for a sustained period and an improvement is noted by their teachers or parents, then they can be tested with the
Intuitive Colorimeter (patented by the Medical Research Council) ${ }^{6}$ to see whether coloured lenses would help further. Practitioners who can undertake the necessary assessment may be found via the Society for Coloured Lens Prescribers (www. s4clp.org), whose members have subscribed to a code of conduct.

Competing interests: BJWE works as a community optometrist and a small proportion of his patients are treated for visual stress and purchase coloured filters. He also lectures on this topic, with some lectures funded by Cerium Visual Technologies, which manufactures the Intuitive Colorimeter and coloured filters.

Full response at: www.bmj.com/content/349/bmj.g5160/rr/763262.

1 Henderson LM, Taylor RH, Barrett B, Griffiths PG. Treating reading difficulties with colour BMJ 2014;349:g5160. (19 August.)

Allen PM, Evans BJW, Wilkins AJ. Vision and reading difficulties. Ten Alps, 2010

3 Kriss I, Evans BJW. The relationship between dyslexia and Meares-Irlen syndrome. $J$ Res Reading 2005;28:350-64

4 Singleton C, Henderson LM. Computerized screening for visual stress in children with dyslexia. Dyslexia 2007;13:130-51.

5 Uccula A, Enna M, Mulatti C. Colors, colored overlays, and reading skills. Front Psychol 2014;5:833.

6 Wilkins AJ, Evans BJ, Brown J, Busby AE, Wingfield AE, Jeanes RJ, et al. Double-masked placebo-controlled trial of precision spectral filters in children who use coloured overlays. Ophthal Physiol Opt 1994;14:365-70.

Cite this as: BMJ 2014;349:95882

๑ BMJ Publishing Group Ltd 2014 